\title{
Fetomaternal interactions and influences during equine pregnancy
}

\author{
W. R. (Twink) Allen \\ Thoroughbred Breeders' Association, Equine Fertility Unit, Mertoun Paddocks, \\ Woodditton Road, Newmarket, Suffolk CB8 9BH, UK
}

\begin{abstract}
The equine embryo takes 6 days to traverse the oviduct and, when it finally enters the uterus, it remains spherical in shape and moves continually throughout the uterine lumen until day 17 after ovulation to deliver its maternal recognition of pregnancy signal to the entire endometrium. Between day 25 and day 35 after ovulation, the trophoblast cells of a discrete annulate portion of the chorion multiply rapidly and acquire an invasive phenotype and, between day 36 and day 38, migrate deeply into the maternal endometrium to form the equine-unique endometrial protuberances known as endometrial cups. These cups secrete large quantities of a gonadotrophic hormone (eCG) into the maternal circulation which, in conjunction with pituitary $\mathrm{FSH}$, stimulates the development of accessory luteal structures in the maternal ovaries to supplement the supply of progesterone to maintain the pregnancy until the placenta can assume this role at about day 100 . The non-invasive allantochorion extends slowly to fill the uterus by days 80-85 and its microcotyledonary architecture, which provides both haemotrophic and histotrophic nutrition for the growing fetus, is not fully established until days 120-140. The fetoplacental unit synthesizes large quantities of steroid hormones during the second half of pregnancy, using fetal C-19 precursors secreted by the enlarged fetal gonads for the production of oestrogens and maternal C-21 precursors for the synthesis of progesterone and large quantities of $5 \alpha$-reduced progestagens. Near term, additional pregnenelone is secreted by the fetal adrenal glands so that the mare exhibits the unusual phenomenon of foaling while maternal serum progestagen concentrations are increasing and oestrogen concentrations are decreasing.
\end{abstract}

Continuous fetomaternal dialogue is a prerequisite of pregnancy in mares, as it is in all mammals. However, a number of features of equine pregnancy are unique to this genus and differ from equivalent events in other common large domestic animal species. It is difficult to provide a precise evolutionary reason for the occurrence of some of these equine-specific oddities of gestation but nonetheless they must be presumed to be important components of the establishment and maintenance of pregnancy. This review aims to highlight these unique features of equine pregnancy and to discuss their significance in terms of the interaction between fetal and maternal organisms for the production of a viable and healthy foal.

\section{Oviductal transport}

van Niekerk and Gerneke (1966) first drew attention to the differential transport of oocytes and embryos within the

Fax: $+44(0) 1638667207$ equine oviduct (Fig. 1). The unfertilized oocyte travels only as far as the ampullary-isthmus junction in mares, where it lodges in the convoluted folds of oviductal mucosa and degenerates over many months (Flood et al., 1979a). However, the equine zygote passes all the way down the oviduct and enters the uterus through the prominent uterotubal papilla between days 6 and 7 after ovulation (Webel et al., 1977; Battut et al., 1998). Thus, flushing of the oviducts of mares post mortem typically yields multiple, degenerate oocytes accumulated from sterile ovulations in preceding oestrous cycles (Betteridge and Mitchell, 1974; David, 1975). However, the sudden occurrence of fertilization can result in the young embryo bypassing the aggregated oocytes to enter the uterus at the expected time (Onuma and Ohnami, 1975).

A series of elegant experiments involving both the recovery and culture in vitro of early stage embryos (Weber et al., 1991a; Freeman et al., 1992) and the surgical implantation of hormone-secreting minipumps onto the mesosalphinx of mares at various times after ovulation (Weber et al., 1991b, 1992, 1995) have provided the 


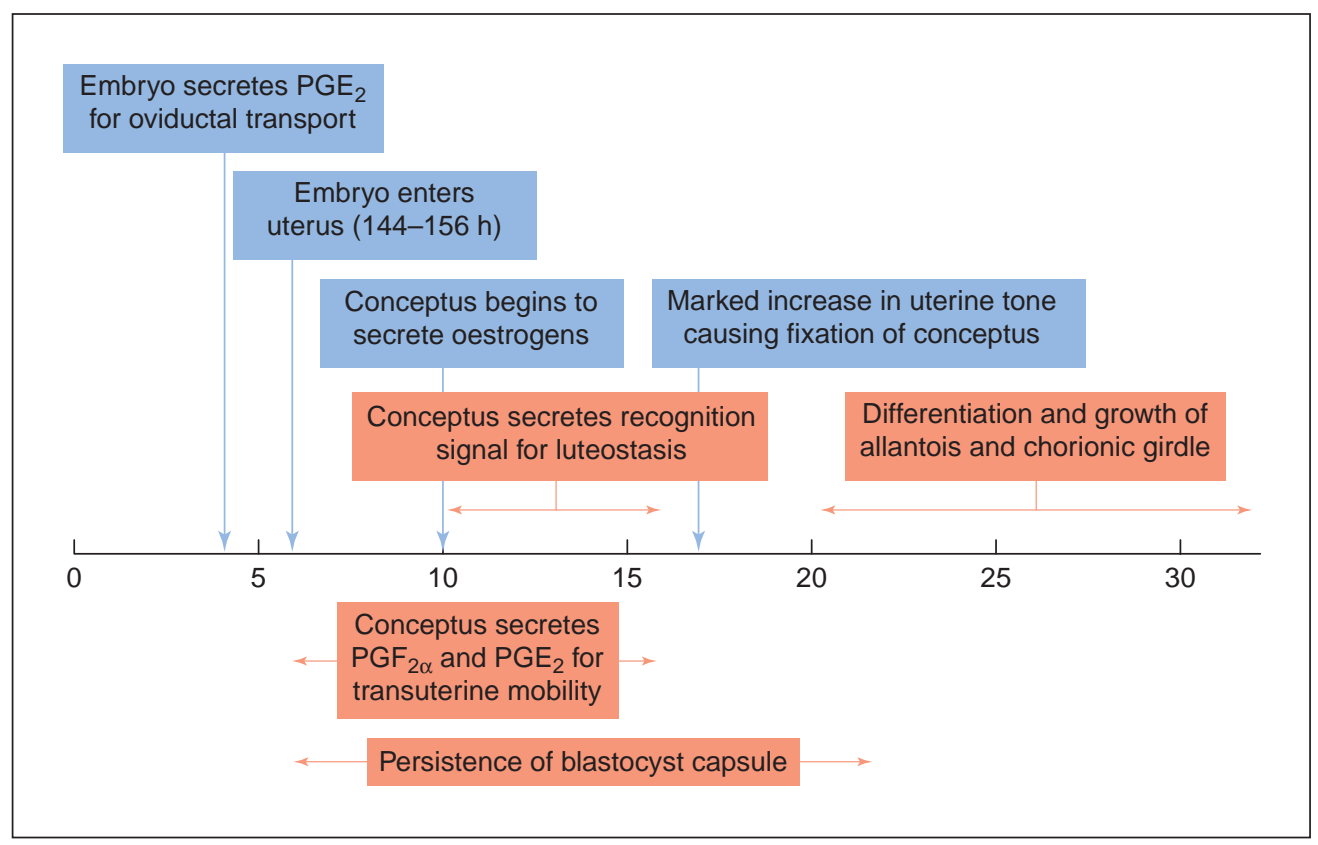

Fig. 1. Some significant events involved in the establishment of pregnancy in the mare. The embryo enters the uterus on day 6 after ovulation as a result of the $\mathrm{PGE}_{2}$ it begins to secrete between day 4 and day 5 and it remains spherical as a result of the presence of the blastocyst capsule and mobile within the uterine lumen until day 17 as a consequence of the peristaltic myometrial contractions induced by the $\mathrm{PGF}_{2 \alpha}$ and $\mathrm{PGE}_{2}$ it secretes. The allantois replaces the yolk sac and the invasive chorionic girdle differentiates on the chorion between these two membranes between day 20 and day 35 .

definitive answer to the oviductal transport puzzle. These experiments demonstrated convincingly that the embryo, but not the oocyte, begins secreting appreciable quantities of prostaglandin $E_{2}\left(P_{G} E_{2}\right)$ when it reaches the compact morula stage of development on day 5 after ovulation. This embryonic hormone acts locally to relax the circular smooth muscle fibres in the wall of the oviduct, allowing rapid onward movement and entry into the uterus some $24 \mathrm{~h}$ later. Thus, it is development of the hormone-secreting capacity of the embryo itself, not any subtle change in maternal recognition of its size, or configurational changes in its outermost coat, that brings about its desired onward passage to the uterus.

The 6 days spent by the equine embryo in the oviduct cause practical difficulties for embryo transfer and related technologies in mares. For example, the success rate when freezing horse embryos in liquid nitrogen decreases sharply with increasing age and size of the embryo (Skidmore et al., 1991), due probably to a combination of freezing damage to the unusually small inner cell mass (ICM) of the equine blastocyst compared with that of cattle and other species (Webel et al., 1977; Skidmore et al., 1991) and the relative impermeability of the equine blastocyst capsule to glycerol and other cryoprotectants (Seidel, 1997). Similarly, the bisection of horse embryos to produce monozygotic (identical) twins is successful when performed on morulae, but the rate falls off markedly if the embryo is showing even the earliest signs of blastulation when it is cut in half (McKinnon et al., 1989; Skidmore et al., 1989).

Weber et al. (1991b) achieved a major advance when they demonstrated accelerated oviductal transport and premature entry of the embryo into the uterus on day 5 after ovulation in mares in which a minipump giving a low-dose, slow-release of $\mathrm{PGE}_{2}$ was implanted surgically on day 4 onto the mesosalphinx ipsilateral to the ovary containing the new corpus luteum. This success stimulated Robinson et al. (2000) to develop a more practical approach to hastening oviductal transport in mares by dripping onto the ipsilateral oviduct on day 4 after ovulation a small volume of a long-acting triacetin-based gel formulation of $\mathrm{PGE}_{2}$ (Dinoprostin; Pharmacia-Upjohn, Crawley, Sussex) applied through a $0.5 \mathrm{ml}$ straw in a disposable plastic equine embryo transfer gun passed through the working channel of a rigid laparoscope inserted into the flank of the mare under local anaesthetic. Non-surgical flushing of the uterus on day 5 yielded a morula from 12 of $20(60 \%)$ mares treated locally with the Dinoprostin, compared with no embryos on day 5 from 19 mares treated similarly with only the gel vehicle, 12 of which (63\%) did produce an expanded blastocyst when their uteri were re-flushed on day 8 (Robinson et al., 2000).

Thus, the riddle of delayed and differential oviductal transport in the mare, posed by the unexpected original discovery of van Niekerk and Gerneke (1966), appears to 

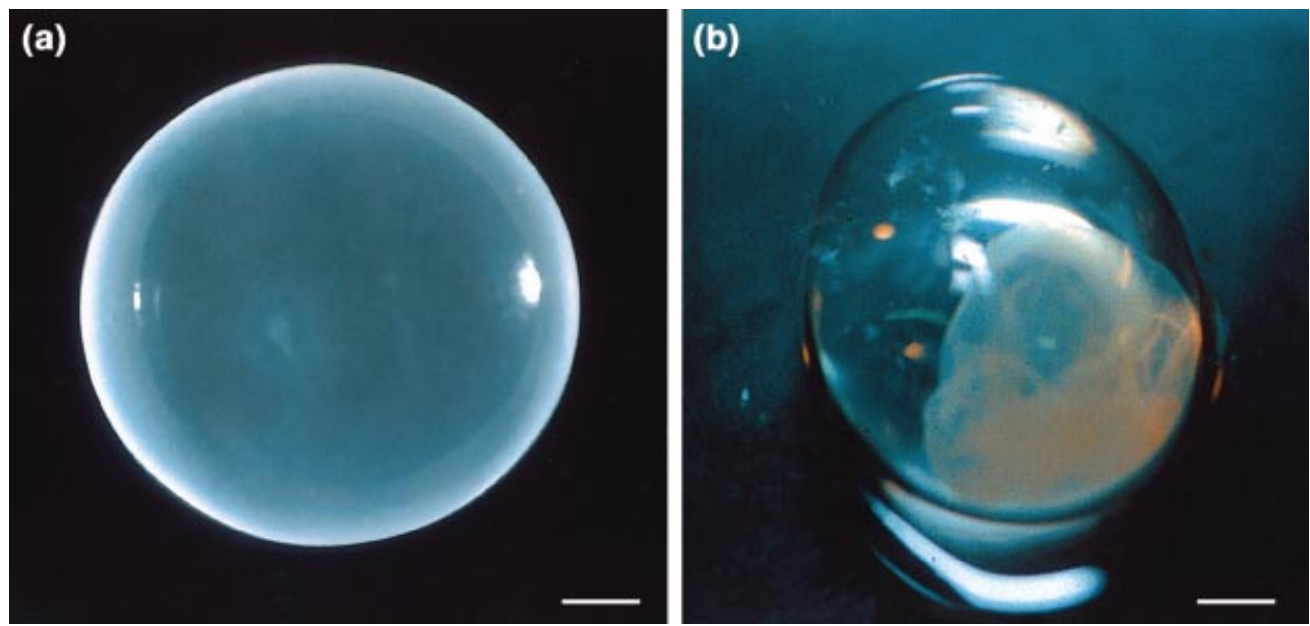

Fig. 2. A horse conceptus at day 14 after ovulation: (a) intact and showing the primitive streak; and (b) with the choriovitelline membrane collapsed to reveal the elastic enveloping blastocyst capsule that normally persists until days $21-23$. Scale bars represent $0.5 \mathrm{~cm}$

have been solved. It is the local smooth muscle-relaxing properties of the stage-dependent secretion of $\mathrm{PGE}_{2}$ by the day 5 morula that is the key to its onward passage into the uterus. However, the question of whether this unusual control of oviductal transport in equids is nothing more than an evolutionary quirk, or is a necessary developmental mechanism to delay entry of the embryo into the uterus until such time as the uterus is hormonally prepared to nurture the embryo, remains of interest for future investigation.

\section{Maternal recognition of pregnancy}

Short (1969) coined the phrase 'maternal recognition of pregnancy' when comparing the different strategies used by the common domestic animal species to ensure continuation of the life and secretory function of the corpus luteum beyond its normal cyclical lifespan, and so maintain the uterus in the correct progestational state to support the pregnancy. A series of elegant experiments in sheep, cows and pigs carried out by R. M. Moor, L. E. A. Rowson, E. J. C. Polge and others at The Animal Research Station in Cambridge earlier in the 1960s (for review, see Moor, 1968) had demonstrated that: (i) the luteolytic hormone that induces cyclical destruction of the corpus luteum is secreted by the uterus; (ii) this uterine luteolysin reaches the ovary via a local vascular pathway instead of the peripheral circulation; and (iii) one or more embryos must be present in the ipsilateral uterine horn between day 12 and day 14 after ovulation to suppress uterine release of luteolysin and so achieve the necessary luteostasis of pregnancy. A further series of experiments in the early 1970 s established that: (i) prostaglandin $\mathrm{F}_{2 \alpha}\left(\mathrm{PGF}_{2 \alpha}\right)$ is the essential component of the uterine luteolysin in mammals; (ii) $\mathrm{PGF}_{2 \alpha}$ is released from the endometrium in spike-like bursts late in dioestrus; and (iii) $\mathrm{PGF}_{2 \alpha}$ reaches the corpus luteum via direct local countercurrent transfer between the uterine vein and the ovarian artery in the ovarian pedicle (for review, see McCracken et al., 1984).

Bazer and Thatcher (1977) first developed the hypothesis that embryonic oestrogens function as the maternal recognition of pregnancy signal in the pig, by redirecting the flow of endometrial $\mathrm{PGF}_{2 \alpha}$ away from the uterine venous drainage towards an exocrine secretory route into the uterine lumen instead. However, vigorous experimental activity in the 1980s and early 1990s demonstrated that, in sheep, cows and other ruminants, the synthesis and release of large quantities of a protein hormone, interferon tau, by the elongating trophoblast between day 10 and day 16 after ovulation suppresses the normal cyclical development of oxytocin receptors in the endometrium (Lamming et al., 1995) which, in turn, prevents oxytocin secreted by the corpus luteum (Flint and Sheldrick, 1982) from binding to the endometrium and driving the pulsatile releases of $\mathrm{PGF}_{2 \alpha}$ that would normally induce luteolysis in the cyclic animal (for reviews, see Lamming and Mann, 1995; Hansen et al., 1999).

The manner in which the embryo transmits the maternal recognition of pregnancy signal in early gestation in mares is in distinct contrast to that in pigs and ruminant species. Between day 6.5 and day 22 after ovulation, the equine embryo is completely enveloped by a tough, elastic glycocalyx known as the equine blastocyst capsule (Fig. 2; Betteridge, 1989). This material is secreted initially by the trophectoderm cells and, owing to the presence of the zona pellucida, it becomes moulded as it hardens into a thin, contiguous membrane that completely envelops the embryo beneath the zona pellucida (Oriol, 1993a). This close fitting capsule around the equine embryo prevents the trophoblast from elongating between day 10 and day 16 
after ovulation, as this tissue does in pig and ruminant embryos to bring the supply tissue, the trophoblast, in direct contact with the target tissue, the endometrium, to maximize local transmission and receipt of the maternal recognition of pregnancy factor (Perry et al., 1973; Wooding, 1982). Instead, the equine embryo remains spherical and completely unattached within the uterine lumen, where it moves constantly throughout the uterine domain, propelled by strong, peristaltic contractions of the myometrium (Fig. 1; Ginther, 1983a, 1985). This unusual process of conceptus mobility in mares persists until day 17 , when a sudden and spasm-like increase in myometrial tone immobilizes and 'fixes' the still spherical vesicle at the base of one or other of the uterine horns (van Niekerk, 1965; Ginther, 1983b).

It is now clear that the constant movement of the equine conceptus throughout the uterus between day 7 and day 17 is necessary to ensure that its maternal recognition of pregnancy signal can be released directly onto the endometrium in all parts of the uterus. The utero-ovarian pedicle in ruminants, which enables ipsilateral countercurrent transfer of $\mathrm{PGF}_{2 \alpha}$ to the ovarian artery, is absent in equids and so endometrial $\mathrm{PGF}_{2 \alpha}$ can reach the ovaries only via the peripheral circulation (Ginther et al., 1972). Indeed, surgical restriction of the equine conceptus to one third of the total uterine surface area results in luteolysis and a return to oestrus, regardless of whether the unoccupied portion of the uterus is ipsilateral or contralateral to the ovary containing the corpus luteum (McDowell etal., 1985).

The nature of the embryonic signal for luteostasis in mares remains a mystery. Unlike the ruminant embryo, the equine conceptus does not produce any interferon-like molecules with anti- $\mathrm{PGF}_{2 \alpha}$ release properties (Baker et al., 1991) but, like the pig embryo, it does begin to secrete appreciable quantities of oestrogens from as early as day 10 after ovulation (Heap et al., 1982). However, in contrast to the situation in pigs, many experiments undertaken over the years to investigate whether embryonic oestrogens are the anti-luteolytic factor of pregnancy in mares have given equivocal results (Berg and Ginther, 1978; Woodley et al., 1979; Stout, 1997). Nevertheless, recent experiments have established that, as in ruminants, suppression of the normal cyclical upregulation of oxytocin receptors in the endometrium between day 10 and day 16 after ovulation is an integral part of the luteostatic mechanism of pregnancy in mares. Endometrial oxytocin receptor concentrations are greatly reduced in pregnant versus cyclic mares between day 10 and day 16 (Starbuck et al., 1998) and the normal spike-like releases of $\mathrm{PGF}_{2 \alpha}$ from the endometrium in response to a bolus injection of oxytocin between day 10 and day 16 in cyclic mares are abolished during the same period in pregnancy (Goff et al., 1987; Starbuck et al., 1998). Curiously, the oxytocin that forms this positive feedback loop with $\mathrm{PGF}_{2 \alpha}$ to induce luteolysis in cyclic mares is secreted by the endometrium (Watson et al., 1997; Stout et al., 2000), as it is in pigs (Boulton et al., 1996), in contrast to the situation in ruminants in which the oxytocin involved in the luteolytic pathway is secreted by the corpus luteum itself (Wathes and Swann, 1982).

Another feature of early pregnancy in mares is the ability of the young conceptus to secrete both $\mathrm{PGF}_{2 \alpha}$ and $\mathrm{PGE}_{2}$ when cultured in vitro (Stout and Allen, 1996). This prostanoic synthetic capacity is probably necessary to stimulate locally the peristaltic contractions of the myometrium that are required to propel the conceptus throughout the uterine lumen during the period of release of the maternal recognition of pregnancy factor. Indeed, conceptus movement is abolished when the pregnant mare is treated systemically with the prostaglandin synthetic inhibitor, flumixin meglumine (Finadyne, Schering Plough, Middlesex; Stout et al., 2000). It is ironic that to distribute its all important recognition message throughout the uterus and ensure its survival in a progesterone-dominated environment, the conceptus must secrete the very hormone, $\mathrm{PGF}_{2 \alpha}$ it is striving to inhibit the maternal endometrium from releasing (Fig. 1). Some of the relatively high proportion of the total pregnancy losses in Thoroughbred mares that occur between day 12 and day 30 after ovulation (32\%, Morris and Allen, in press) may stem not from a failure of release of sufficient maternal recognition of pregnancy factor from the conceptus to suppress the cyclical luteolytic pathway, but perhaps from the secretion of too much PGF $_{2 \alpha}$ by the wandering conceptus, which then gains untoward access into the peripheral circulation and accidentally induces luteolysis of the corpus luteum.

\section{Embryogenesis and fetal membrane development}

In addition to providing strength to the expanding blastocyst to enable it to withstand the rigours of the myometrial contractions that propel it through the uterus (Betteridge, 1989), the blastocyst capsule is also important in regulating the supply of nutrients to the embryo. Owing to its negative electrostatic charge and unusual glycocalyx configuration (Oriol et al., 1993b), the outer surface of the capsule is very sticky towards other proteins (Fig. 2). Therefore, the capsule accumulates onto its surface a range of proteins and other components of endometrial gland secretions as the conceptus moves through the uterus between day 7 and day 17 after ovulation. This process of accumulating what may be presumed to be the only source of nutrients for the rapidly growing conceptus ('uterine milk'; Amoroso, 1952) is evidenced by a doubling or more in mass of the capsule between emergence of the blastocyst from the zona pellucida between days 7 and 8 after ovulation and immobilization of the conceptus on about day 17 (Oriol et al., 1993a) and also by the very large quantities of the progesterone-dependent, 19 kDa endometrial gland protein, P19, which adheres to the capsule (Stewart et al., 1995a).

The capsule begins to disintegrate from about day 20-21, presumably as a result of the action of proteolytic enzymes secreted by the trophoblast or the luminal epithelium of the endometrium (Denker et al., 1987). This disintegration allows the rapid development of areolae-like tufts of tro- 


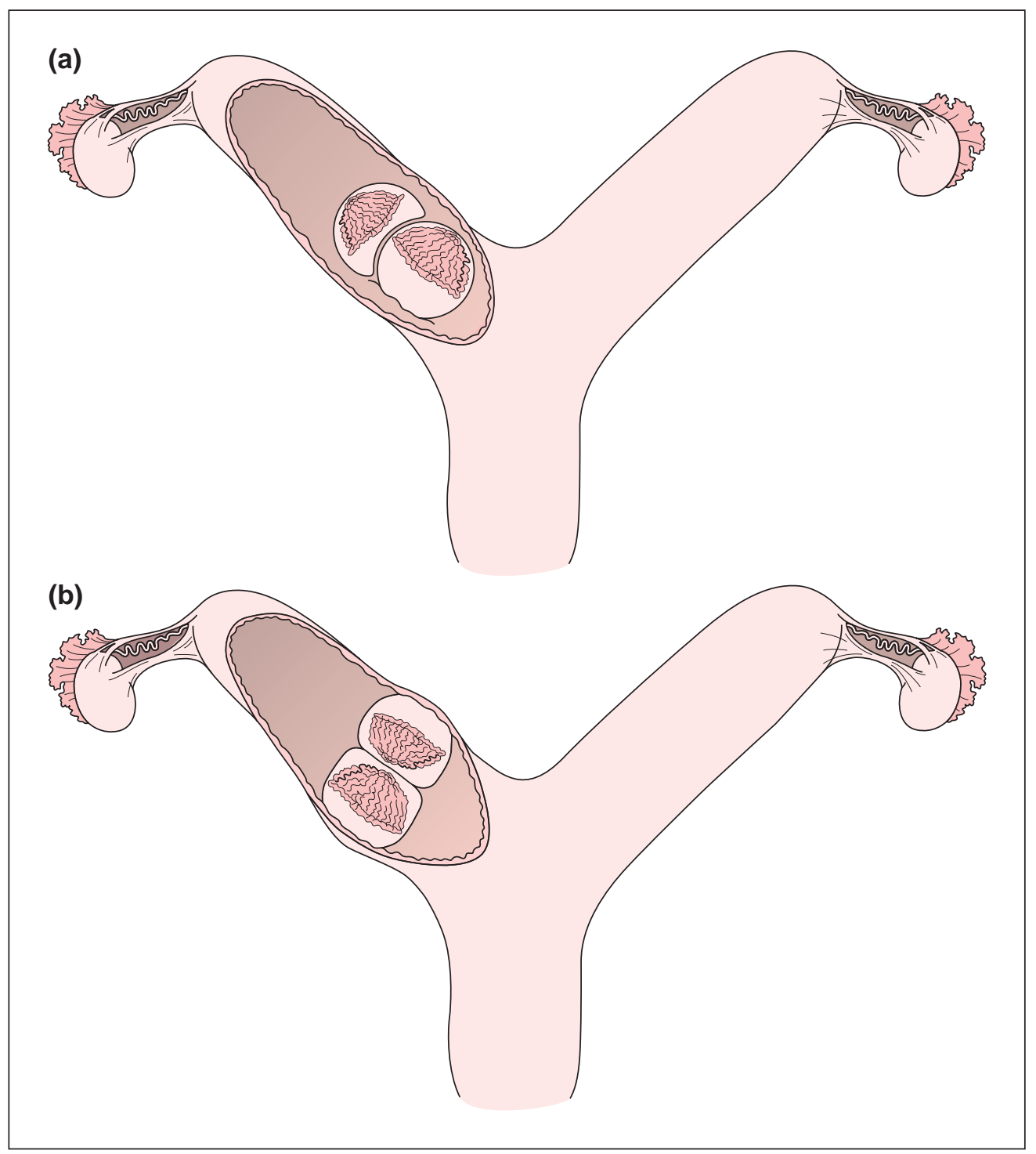

Fig. 3. Representation of two possible positions for day 18 unicornuate twin conceptuses in the uterus of the mare. In (a), the non-vascularized but highly absorptive bilaminar choriovitelline membrane of the more anterior conceptus is abutted onto the membranes of its twin and therefore is prevented from imbibing endometrial gland secretions ('uterine milk') for sustenance. In contrast, in (b), the choriovitelline membranes of both conceptuses are abutted to endometrium and therefore can function normally.

phoblast cells on the external surface of the as yet nonvascularized choriovitelline membrane that protrude into the mouths of the endometrial glands, both for more efficient imbibition of the gland secretions and to give physical adherence of the conceptus to the endometrium. The nutritional importance of these temporary areolae (Amoroso, 1952) is indicated by the high rate $(70-80 \%)$ of spontaneous death and resorption of one of twin conceptuses between day 18 and day 30 in Thoroughbred mares (Morris and Allen, in press), which occurs when both conceptuses become 'fixed' at the base of the same uterine horn (unicornuate twins) in such a manner that the absorptive bilaminar choriovitelline portion of one conceptus abuts against the membranes of its co-twin rather than against the nutritionally provident endometrium (Fig. 3; Ginther, 1985; Morris and Allen, in press). At about day 21 after ovulation, the embryo, with its primitive beating heart, can be discerned at one pole of the still-spherical conceptus (van Niekerk and Allen, 1975) and the allantois is just appearing as an outpouching of its hind gut (Ewart, 1915). The latter grows rapidly to surround the embryo and fuse with the outer chorion so that, by day 28 , the resulting 

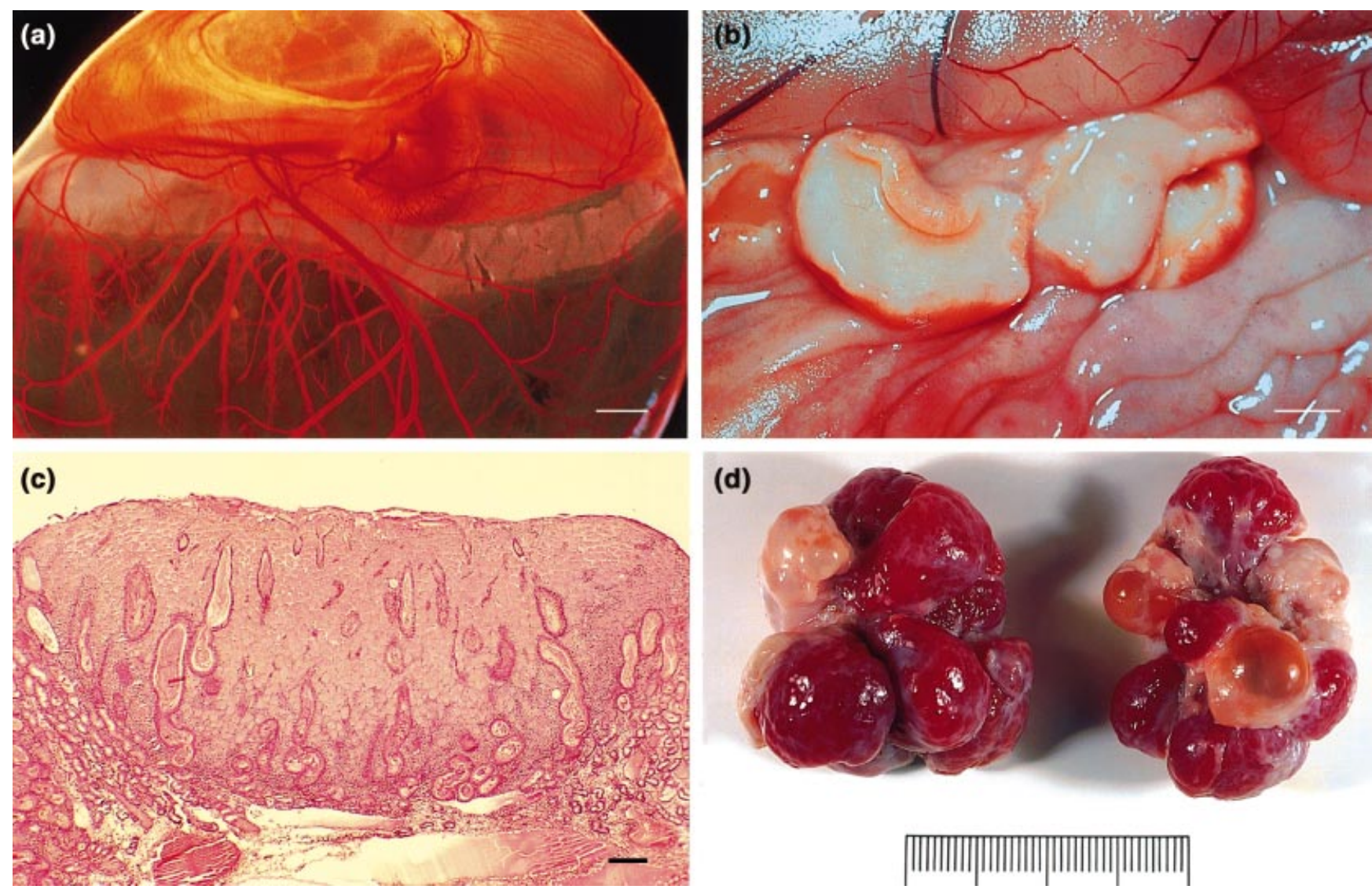

Fig. 4. (a) Intact horse conceptus at 35 days after ovulation showing the thickened, white chorionic girdle just before its invasion into the maternal endometrium to form the eCG-secreting endometrial cups. (b) The allantochorion retracted at day 85 of gestation to reveal the typical saucer-shaped endometrial cups beneath it. The central depression of one of the endometrial cups is filled with sticky, honeycoloured eCG-rich exocrine secretion. (c) Low power photomicrograph of a section of an endometrial cup recovered from a mare at day 60 of gestation and showing the tightly packed mass of large eCG-secreting fetal endometrial cup cells, interspersed with the dilated fundic portions of the endometrial glands and accumulating maternal lymphocytes and other leucocytes in the surrounding stroma. (d) The ovaries from a mare at day 118 of gestation with the tunica albuginica dissected away to show the multiple secondary luteal structures that had developed sequentially during the previous 80 days in response to the LH-like action of eCG on waves of follicles stimulated by the continuing secretion of pituitary FSH. Scale bars represent (a) $0.5 \mathrm{~cm}$, (b) $1.0 \mathrm{~cm}$, (c) $0.2 \mathrm{~cm}$ and (d) scale shown in millimetres.

allantochorion, with its well vascularized allantoic mesoderm, occupies about one quarter of the total volume of the conceptus (van Niekerk and Allen, 1975).

\section{Endometrial cup reaction}

Between day 25 and day 35 after ovulation, a discrete, annulate thickening of the trophoblast develops on the outer surface of the chorion in the region of abutment of the enlarging allantois and regressing yolk sac membranes (Fig. 4a). This chorionic girdle (Ewart, 1897; van Niekerk, 1965) forms as a series of shallow undulations in the chorion that deepen markedly to become elongated ridges owing to hyperplasia of the trophoblast cells at the top of each fold. The outermost cells release an alcian blue-positive exocrine secretion that 'glues' the outer surface of the chorionic girdle to the luminal surface of the overlying endometrium.
Between day 36 and day 38, the whole girdle simply peels off the underlying fetal membranes and the specialized trophoblast cells begin to invade the maternal endometrium (Allen and Moor, 1972) by passing between, and occasionally straight through (Allen et al., 1973), the luminal epithelial cells to reach the basement membrane. The trophoblast cells track down the endometrial glands, dislodging the glandular epithelial cells as they go, and finally break through the basement membrane and stream out into the endometrial stroma during days 38-40. Next, as though triggered by a developmental time switch, all the invading girdle cells suddenly stop migrating, round up, enlarge greatly and become tightly packed together within the endometrial stroma (Hamilton et al., 1973). The resulting protuberances, described originally by Schauder (1912) and named endometrial cups by Cole and Goss (1943), are first seen at about day 40 as a series of pale, 
raised plaques on the surface of the endometrium, arranged in a circle about the conceptus at the base of the gravid uterine horn (Clegg et al., 1954; Allen, 1975). The endometrial cups range in size from small, circular structures of 1-2 $\mathrm{mm}$ in diameter to long unbroken ribbons of cup tissue that may be $3-5 \mathrm{~cm}$ in width, depending upon the combination of the width and general development of the progenitor chorionic girdle and the configuration of the endometrium it has invaded (Allen and Stewart, 1993).

The cups grow steadily to reach a maximum size and hormone-secreting capacity between day 60 and day 70 of gestation. At this time, they are well raised above the surface of the endometrium and are saucer-shaped or ulcerlike in appearance owing to overgrowth at the edges and commencing cell degeneration and sloughing in the central region (Fig. 4b). Histologically, each cup now consists of a tightly packed mass of the large, binucleate, epithelioid cup cells interspersed with occasional blood vessels and the dilated fundic portions of the endometrial glands (Fig. 4c); the apical portions are obliterated during invasion of the chorionic girdle cells at day 36. Large lymph sinuses form beneath each cup and a steadily increasing number of $\mathrm{CD} 4^{+}$ and $\mathrm{CD}^{+}$lymphocytes (Kydd et al., 1991), together with plasma cells, macrophages and eosinophils (Grünig et al., 1995), accumulates in the stroma at the periphery of the cup (Allen, 1975). After day 70, the cups begin to degenerate owing to death and sloughing of cup cells in the central, luminal depression, combined with the commencement of infiltration of the accumulated leucocytes into the cup tissue, where they attack and destroy the fetal cup cells (Allen, 1975). The cups become increasingly pale and cheesy in appearance and, owing to the re-establishment of the outlets of the distended endometrial glands by cell sloughing at the luminal surface, the accumulated exocrine secretory material is released and mixes with the necrotic cell debris to form a sticky, honey-coloured coagulum, rich in eCG activity (Rowlands, 1963) that accumulates in the central depression of the cup and may adhere to the surface of the overlying allantochorion. Eventually, between day 100 and day 120 in most mares, the whole necrotic cup and its attached, inspissated secretion sloughs off the surface of the endometrium to lie free in the uterine lumen, where it sometimes indents into the allantochorion to form a pendulous sac known as an allantochorionic pouch (Clegg et al., 1954).

This unusual injection of specialized trophoblast cells into the maternal endometrium has both endocrinological and immunological implications for the maintenance of pregnancy. The large fetal endometrial cup cells secrete appreciable quantities of the high molecular weight glycoprotein hormone, equine chorionic gonadotrophin (eCG; Gospodorowicz, 1972), which expresses both FSHlike and LH-like biological activities in a ratio of 1.4:1 (Stewart et al., 1976). Concentrations of eCG in maternal serum increase rapidly from day 40 to variable peak values of 20-300 iu $\mathrm{ml}^{-1}$ between day 50 and day 75 , after which they decline again in parallel with the degeneration of the endometrial cups (Cole and Hart, 1930; Allen, 1969). During this period, the LH-like component of eCG ovulates, or luteinizes without ovulation, the dominant member of successive waves of ovarian follicles that are stimulated to develop throughout the first half of pregnancy by continuation of the light-driven 10-12 day surges of pituitary FSH release that stimulate follicular development during the oestrous cycle (Evans and Irvine, 1975; Urwin and Allen, 1982). Thus, secondary corpora lutea begin to accumulate in the maternal ovaries from the time of the first appearance of eCG in maternal blood (Fig. 3d), with consequential increases in maternal serum progesterone concentrations. These secondary corpora lutea persist until mid-gestation, by which time the diffuse, chorioallantoic placenta is well enough established to take over completely the supply of sufficient progesterone to maintain the pregnancy until term (Cole et al., 1931; Amoroso et al., 1948). In addition to stimulating the increase in progesterone production, eCG also induces a sharp increase in peripheral serumconjugated oestrogen concentrations at days 38-40 (Urwin and Allen, 1982). These oestrogens are ovarian in origin (Terqui and Palmer, 1979) and are secreted by luteal rather than the follicular tissue (Daels et al., 1991). After day 40, the serum oestrogen concentrations plateau, until days 70-80, when a second and more prolonged increase, which is fetoplacental in origin, commences (Cox, 1975). Thus, by means of the gonadotrophic hormone secreted by its specialized component, the endometrial cups, the equine placenta influences the steroid hormone output of the maternal ovaries profoundly, with both progesterone and oestrogen being secreted by the primary and secondary luteal structures.

Immunologically, the endometrial cup reaction is an enigma. The invasive chorionic girdle cells, but not the noninvasive trophoblast of the allantochorion, express high concentrations of paternally inherited class I major histocompatibility complex (MHC) antigens on their surface before, and for a few days after, they invade the maternal endometrium to form the endometrial cups (Crump et al., 1987; Donaldson et al., 1990). The class I MHC antigens stimulate a strong humoral response in the mother such that all mares, including primigravid maidens, carrying fetuses that differ paternally at the class I MHC barrier, develop high titres of specific anti-paternal lymphocytotoxic antibody in their serum within 10-14 days after initial development of the endometrial cups (Antczak et al., 1982; Kydd et al., 1982). The antibody persists throughout pregnancy and its concentration in serum increases markedly at an even earlier stage of gestation in mares mated to the same stallion in successive years (Antczak et al., 1984), and in mares to which biopsies of skin from the stallion have been transplanted before mating (D. F. Antczak, personal communication). In addition, the accumulation of maternal leucocytes about the cups (Fig. 3c) and their role in the destruction of the cup cells after day 70 (Allen, 1975) indicate a strong maternal cell-mediated reaction against the invading trophoblast cells. However, although it is clear that 


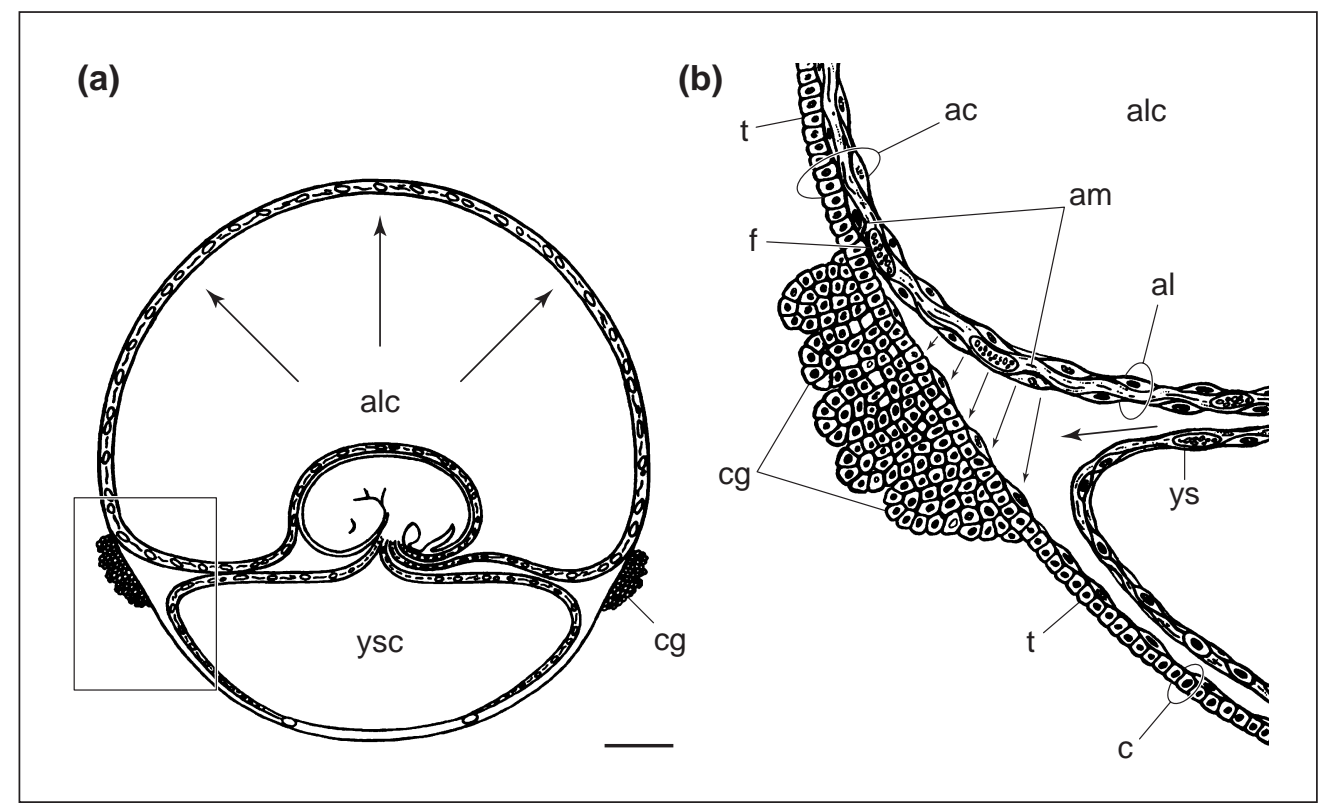

Fig. 5. Representation of the equine conceptus and its membranes at about day 34 of gestation, showing the hypothesized differential development of the allantochorion (ac) and the chorionic girdle (cg) as a result of the mitogenic action of hepatocyte growth factor-scatter factor (HGF-SF) secreted by the allantoic mesoderm (am). al: allantois; alc: allantoic cavity; c: chorion; f: point of infusion; t: trophoblast; ys: yolk sac; ysc: yolk sac cavity. Scale bar represents $1 \mathrm{~cm}$. (Reproduced from Stewart et al., 1995b, with permission.)

the paternal class I MHC antigens expressed by the invading chorionic girdle cells (Donaldson et al., 1990) are the stimulus for the humoral response of the mother to the fetus in pregnancy, the nature and source of the antigens that stimulate this cell-mediated reaction are not clear. The cups live as long, and secrete equivalent amounts of eCG, in mares carrying MHC-incompatible and MHC-compatible fetuses (Allen et al., 1983), and the leucocytic response mounted against the cups is far more intense and destructive in mares carrying interspecific hybrid mule fetuses than in mares carrying normal intraspecific horse fetuses (Allen, 1975). Thus, it appears likely that tissue-specific trophoblast antigens and species-specific non-MHC antigens lie behind the observed maternal cell-mediated responses to the endometrial cups (Allen, 1982; Antczak and Allen, 1984).

In an investigation of how and why the invasive chorionic girdle suddenly develops in the midst of the otherwise non-invasive trophoblast of the allantochorion between day 25 and day 35 of gestation, Stewart et al. (1995b) observed that the girdle is thickest at the edge abutting the allantois and shows a definite thinning at the edge adjacent to the yolk sac (Fig. 5). Furthermore, small blood vessels emanating from the vascularized allantoic mesoderm extend beneath the otherwise non-vascularized chorionic girdle, but only to about halfway across its width. Stewart et al. (1995b) used in situ hybridization techniques to demonstrate that allantoic mesenchyme in the horse conceptus is the major source of the highly mitogenic and motogenic growth factor, hepatocyte growth factor-scatter factor (HGF-SF) at this early stage of gestation. Stewart et al. (1995b) hypothesized that this mesodermal HGF-SF is the principal mitogenic stimulant to both the trophoblast and the allantoic cells during differentiation and expansion of the allantochorion. Since these two component membranes, the chorion and the allantois, are fused together by the mesodermal tissue secreting the mitogen, and since the trophoblast cells are attached firmly to a basement membrane, the mitogen-induced growth occurs as a simple expansion of the allantochorion (Fig. 4a). However, in the chorionic girdle, which is exposed to a 'sliding scale' of mitogenic stimulation by HGF-SF secreted by the extended mesenchymal blood vessels beneath it (Fig. 4b), hyperplastic trophoblast cells can only pile up on each other, rather than expand in a linear manner. Thus, the discrete and thickened chorionic girdle is formed (Stewart et al., 1995b).

Such a scheme of growth factor-driven development of the chorionic girdle might also explain the interactions of fetal genotype and uterine environment on the development of the progenitor chorionic girdle and the hormone output of the resulting endometrial cups. For example, the girdle that develops on the conceptus in donkeys (Equus asinus, $2 \mathrm{n}=62)$ and the hybrid between the female horse ( $E$. caballus, $2 \mathrm{n}=64)$ and the male donkey, the mule (E. mulus 


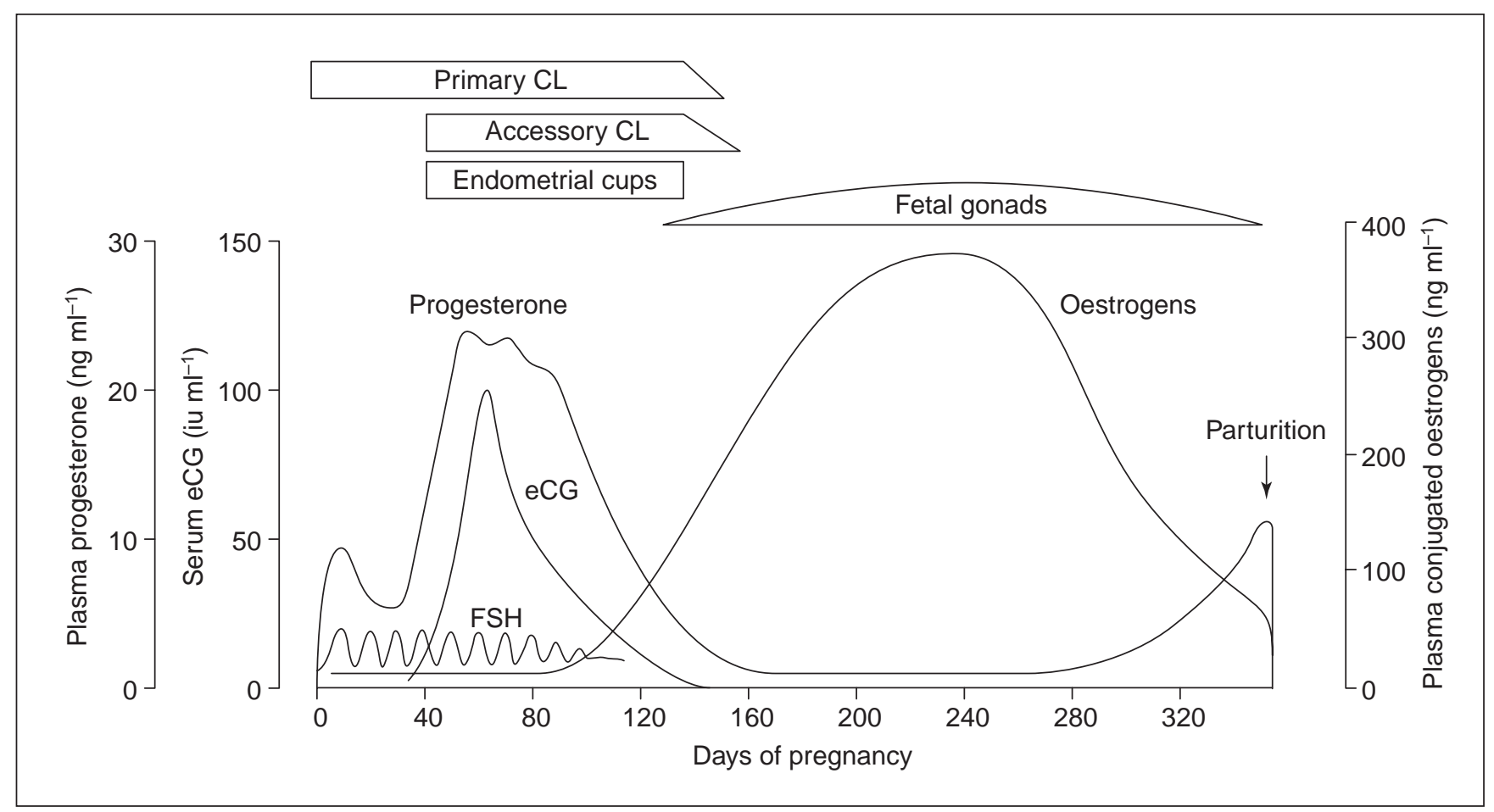

Fig. 6. Summary of major endocrinological events throughout pregnancy in the mare. The endometrial cups are present in the uterus between day 40 and day 120 after ovulation and the gonadotrophin they secrete (eCG) ovulates or lutenizes secondary follicles that are stimulated to develop in the maternal ovaries by continuous 10-12 day surges of FSH released from the pituitary gland. During the second half of gestation, C-19 steroid precursors secreted by the enlarged fetal gonads are aromatized by the placenta to produce very high concentrations of phenolic and ring $\beta$-unsaturated oestrogens in maternal blood and urine. Maternal plasma progestagen concentrations remain low owing to direct endometrial metabolism of the progestagens synthesized by the diffuse placenta, but they increase during the final 4-6 weeks as a result of additional pregnenelone secreted by the maturing fetal adrenal glands.

mulus, $2 \mathrm{n}=63$ ), both of which have a donkey as the sire, is much narrower and less well developed at the time of invasion of the maternal endometrium at about day 36 than the girdle that develops on the horse conceptus and the reciprocal hybrid, the hinny, both of which have a horse as the sire (Allen et al., 1993). It would appear that this difference is caused by maternal imprinting of genes controlling the development of the chorionic girdle portion of the placenta. However, a dominating role of uterine environment on the whole process has been demonstrated in two experiments. In the first experiment, in mares carrying extraspecific donkey-in-horse pregnancies created by embryo transfer, the donkey chorionic girdle develops so badly in the horse uterus that it fails completely to invade the endometrium at about day 36 , with the result that no endometrial cups develop (Allen, 1982). In the second experiment, the transfer of one of the two halves of a bisected mule morula into a recipient mare and the other half into a Jenny donkey, yielded a striking difference in the development of the endometrial cups. The mule conceptus in the mare, in which it would normally develop, produced a typically narrow chorionic girdle that gave rise to small endometrial cups with low eCG output. In sharp contrast, the same (identical twin) mule conceptus in the donkey uterus produced a very wide chorionic girdle that transformed into large and productive endometrial cups that secreted high concentrations of eCG into the blood of the surrogate donkey mother (Allen et al., 1993). Thus, uterine environment over-rode completely any genetic controls that may have been present.

The evolutionary reason behind the development of the endometrial cup reaction in equine pregnancy is difficult to discern. The extra progesterone secreted by the accessory corpora lutea stimulated by the large quantities of eCG secreted by the cups during their short lifespan undoubtedly helps to maintain the pregnancy state until about day 100 when, as shown by the ovariectomy studies of Holtan et al. (1979), the placenta is sufficiently mature to take over completely the supply of progesterone without further contribution from the ovaries (Fig. 6). However, as demonstrated by the survival to term of about $30 \%$ of extraspecific donkey-in-horse pregnancies in the absence of any secondary luteal development as a result of failure of development of endometrial cups (Allen et al., 1987), secondary luteal progesterone is not essential to the maintenance of early pregnancy in mares. 


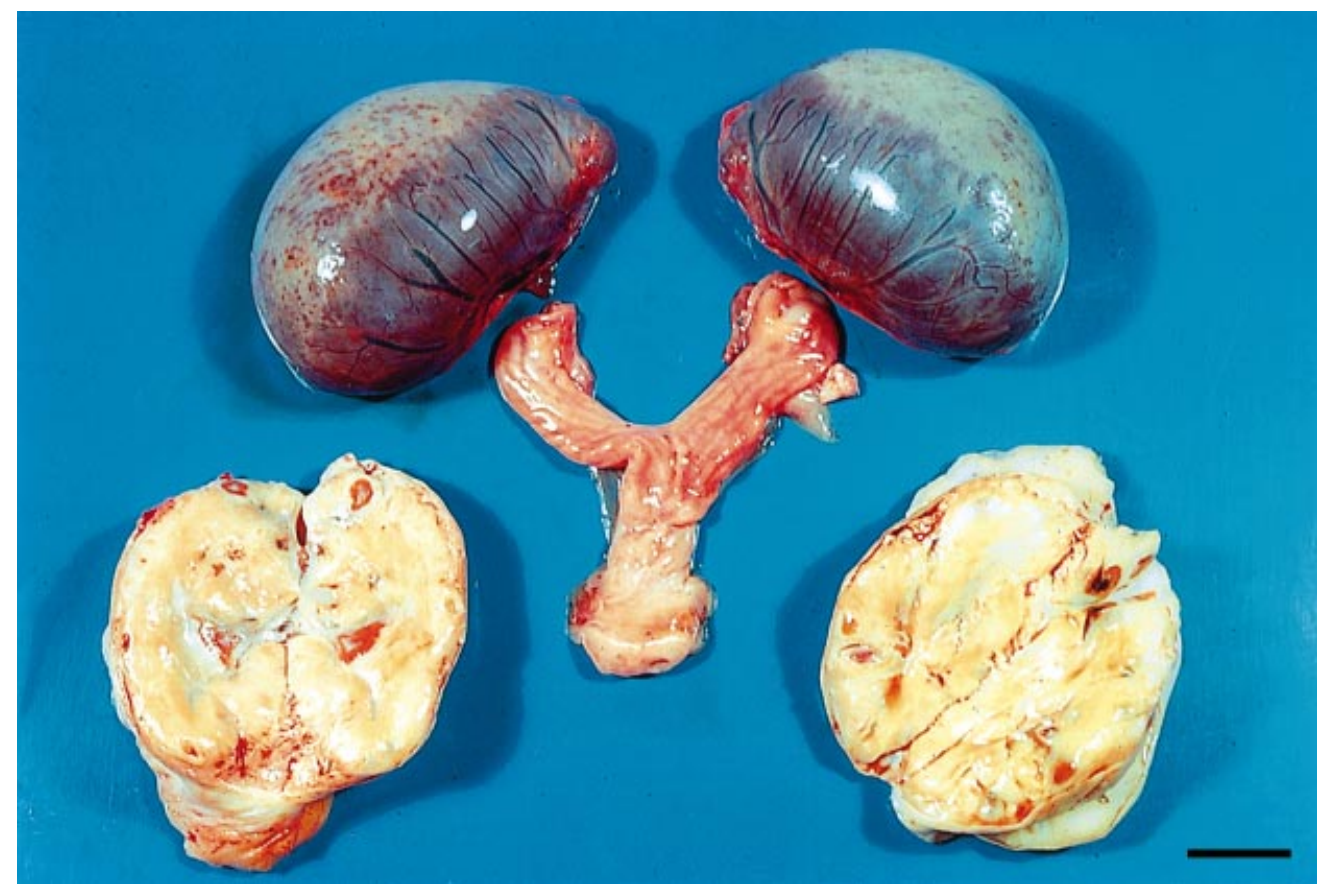

Fig. 7. The inactive maternal ovaries and the greatly enlarged fetal ovaries and undeveloped fetal uterus recovered from a pregnant mare on day 253 of gestation. Scale bar represents $2 \mathrm{~cm}$.

Immunologically, it must be a risky stratagem for any allogenic fetus to immunize its dam against its paternally derived histocompatibility antigens, merely to generate some extra luteal progesterone that is not absolutely necessary. Yet, curiously, it is the one type of equine pregnancy that does not produce endometrial cups, the extraspecific donkey-in-horse pregnancy, that suffers the very high rate (approximately $70 \%$ ) of pregnancy loss between day 80 and day 100 of gestation that is characterized by delayed or inadequate development of the noninvasive placenta and an intense and generalized maternal leucocytic response throughout the area of endometrium in direct contact with the xenogenic donkey trophoblast (Allen, 1982). Moreover, administration of high doses of either or both eCG and progestagens to mares carrying donkey fetuses fails to reduce the high rate of pregnancy loss (Allen, 1982), whereas active immunization of the surrogate mares early in pregnancy against donkey lymphocytes markedly increases fetal survival rate above that observed in untreated control mares (Allen et al., 1987). The lack of normal interdigitation between the allantochorion and the endometrium is the most striking feature of the unsuccessful donkey-in-horse pregnancy model in which endometrial cups do not develop and the associated maternal humoral and cell-mediated responses are absent. This lack of interdigitation raises the possibility that some, as yet unrealized, influence of the endometrial cup reaction in equids is an essential and temporally important stimulus for initiating the stable microvillous connection between the fetal and maternal epithelial layers in the uterus, which is the cornerstone of the whole process of placentation in this genus.

\section{Fetal gonad enlargement}

Another oddity of equine pregnancy is the enormous growth and subsequent regression exhibited by the fetal gonads during the second half of gestation (Cole et al., 1933). At about day 80 in both male and female fetuses, the gonads begin to enlarge steadily until they reach a maximum size and a combined mass of approximately $350 \mathrm{~g}$ between day 230 and day 260. At this time, they occupy as much as one third of the total volume of the abdominal cavity of the fetus and have much more the appearance of a kidney than the differentiated gonad they will eventually become (Fig. 7). The ovaries are distinguishable from the testes by a pale layer of primordial oocytes in the cortical region of the organ and, histologically, both sexes exhibit masses of large, epitheloid interstitial cells supported within a fibrous tissue framework through which numerous blood and lymph vessels run. Germinal elements are limited to a narrow cortical zone in female fetuses and scattered cords in the male fetuses (Hay and Allen, 1975; Merchant-Larios, 1979). The gonads begin to shrink again after day 270 and, by term at about day 336, have reduced in size and appearance to small, relatively insignificant structures similar to the neonatal gonads of other large domestic animals. 
In close parallel with the enlargement and regression of the fetal gonads, maternal serum oestrogen concentrations increase steadily to a variable peak value as high as $400 \mathrm{ng}$ $\mathrm{ml}^{-1}$ between day 190 and day 250 of gestation and decline thereafter to baseline values at term (Cox, 1975). The maternal oestrogens at this time include both the common phenolic oestrogens, oestrone and oestradiol, and the equine-unique ring $\beta$-unsaturated oestrogens, equilin and equilenin (Gaudry and Glen, 1959; Raeside and Liptrap, 1975).

A series of elegant fetal infusion experiments in the late 1960s established that the oestrogens in pregnant mares are produced by placental aromatization of large quantities of dehydroandrosterone (DHA), dehydroepiandrosterone (DHEA) and unusual $3 \beta$ hydroxylated C-19 DHEA-like precursors secreted by the interstitial cells of the enlarged fetal gonads (Bhavnani et al., 1969, 1971; Bhavnani and Short, 1973a,b) in a similar manner to the large quantities of oestrogens, including the pregnancyspecific oestriol, produced in women by placental aromatization of DHA and DHEA secreted by the enlarged fetal adrenals (Diczfalusy, 1969). Subsequently, Tait et al. (1983) confirmed the production of large quantities of the ring $\beta$-unsaturated precursors, 3 $\beta$-hydroxy-5,7pregnanedien-20-one and 3 $\beta$-hydroxy-5,7-androstadien17-one, by the fetal gonads.

The biological functions of these very large quantities of oestrogens in pregnant mares has remained a puzzle since Pashen and Allen (1979) demonstrated that all of four pony mares that underwent bilateral fetal gonadectomy between day 197 and day 253 of gestation remained pregnant and underwent spontaneous parturition between day 294 and day 323, despite an immediate and precipitous decrease in maternal serum concentrations of both conjugated and free oestrogens after removal of the fetal gonads. However, the gonadectomized foals were born appreciably lighter and less well muscled than their three sham-gonadectomized controls, and their births, although spontaneous in onset, were characterized by weak myometrial contractions, lower than normal releases of $\mathrm{PGF}_{2 \alpha}$ into maternal blood and retained placentae (Pashen and Allen, 1979). This retarded growth in the gonadectomized foals may have been mediated by a reduction in uteroplacental blood flow since oestrogens and their precursors had been shown previously to influence markedly the rate of blood flow through the uterine and placental vessels in ewes (Resnik et al., 1974; Pupkin et al., 1975). Thus, Pashen and Allen (1979) hypothesized that the primary function of the large quantities of placental oestrogens produced in pregnant mares is to stimulate fetal growth by exerting a positive influence on uterine and placental blood flows.

\section{Placentation}

It is not until as late as day 40 after ovulation that the noninvasive trophoblast of the allantochorion at last begins to establish a stable, microvillous attachment to the luminal
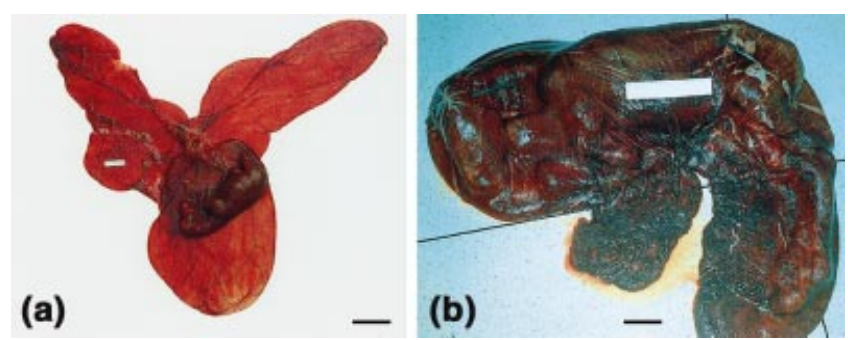

Fig. 8. Intact horse conceptus at (a) day 93 and (b) day 268 of gestation showing the extensive area of non-invasive allantochorion for placental exchange and the thickening in later gestation owing to the continuing development of the microcotyledonary exchange units. The scar-like areas devoid of microcotyledons situated at the base of the gravid horn and highlighted by the artery forceps had overlain the endometrial cups earlier in pregnancy. Scale bars represent $4 \mathrm{~cm}$.

epithelial cells of the endometrium (Samuel et al., 1975). The allantochorion elongates steadily over the next 40 days until it occupies the whole of the interior of the uterus by days 80-85 (Fig. 8). At this expanding fetomaternal interface, blunt, finger-like villi of allantochorion begin to interdigitate with thinner, frond-like upgrowths from the surface of the endometrium, somewhat akin to the insertion of fingers into a tight-fitting glove (Samuel et al., 1974). After about day 60, these allantochorionic villi and their accommodating endometrial sulci begin to branch extensively, while at the same time becoming longer and deeper. The process continues until, by about day 120 (Bracher et al., 1996), the primary haemotrophic exchange unit of the non-invasive allantochorionic placenta, the microcotyledon, is formed (Fig. 9; Samuel et al., 1975). Further development persists throughout gestation to maximize the area of contact between the fetal and maternal epithelial layers for haemotrophic transfer of nutrients and waste products, and the exchange process is aided by the indentation of blood capillaries into the bases of these epithelial layers on both the fetal and maternal sides of the interface (Samuel et al., 1976; Macdonald et al., 2000). Each microcotyledon is supplied by a sizeable artery on the maternal side and an equivalent placental artery on the fetal side to maximize the haemotrophic exchange process (Fig. 9; Steven and Samuel, 1975). In addition, the long, convoluted and multi-branched endometrial glands also remain functional throughout gestation, liberating their protein-rich exocrine secretions into well defined spaces between adjacent microcotyledons termed areolae (Fig. 8). The trophoblast cells overlying the gland openings become pseudostratified and appear to be specially adapted to take up these droplets of uterine milk (Amoroso, 1952). Thus, a second, and no doubt equally important, form of histotrophic nutrition is established to help supply the demands of the rapidly growing fetal foal (Samuel et al., 1977). 


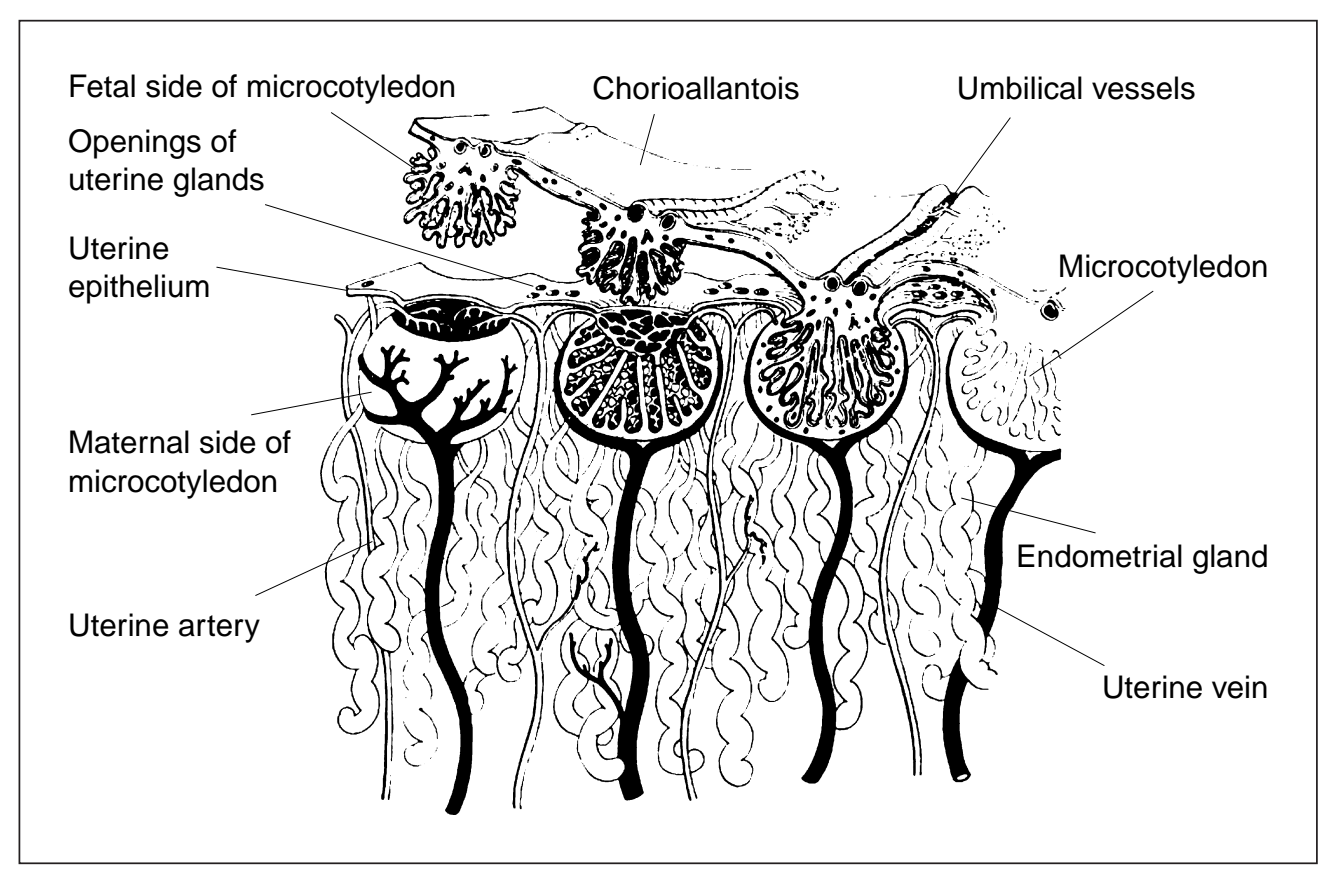

Fig. 9. Representation of the structure and vascularization of the mature microcotyledons and intervening areolae in the equine placenta. (Reproduced from Steven and Samuel, 1975, with permission.)

The nature of the stimuli that finally initiate placental interdigitation at about day 40 in pregnant mares, and which drive the growth and modification of the endometrium and allantochorion throughout gestation, are of some interest. Locally produced growth factors are the most likely candidates to provide this mitogenic impetus to placentation, and Stewart et al. (1995b) and Lennard et al. (1998) described the occurrence of a sudden and marked upregulation in the mRNA for epidermal growth factor (EGF) in just the apical portions of the endometrial glands in pregnant mares between day 35 and day 40 after ovulation. Furthermore, Gerstenberg et al. (1999) demonstrated that this upregulation in endometrial EGF production is stimulated not by eCG or oestrogens, but solely by the continuous 35 day period of increased progesterone secretion associated with pregnancy. Another mitogenic growth factor, insulin-like growth factor II (IGF-II), is secreted by the trophoblast and many other embryonic and fetal tissues from as early as day 20 after ovulation in pregnant mares (Lennard et al., 1995). It is likely that these two growth factors, EGF from the maternal endometrial glands and IGF-II from the fetal tissues, play fundamental roles in initiating and maintaining the remarkable hyperplasia and architectural re-modelling of the endometrium and allantochorion that occurs during the development of the mature, diffuse, non-invasive, epitheliochorial equine placenta.

\section{Conclusions}

Thus, from the beginning to the end of gestation, the mare stands in sharp contrast to other large domestic animal species in many of the structural and functional features that combine to induce and support pregnancy. The embryo takes 6 days to traverse the oviduct and must supply its own hormone power to achieve that objective. It remains spherical and unattached for a protracted period in the uterine lumen, where it moves continually throughout that domain, again by means of its own hormone power. When, at last, the conceptus embarks upon the process of implantation and placental attachment, it must first differentiate a discrete portion of its trophoblast into an invasive phenotype and literally inject these cells into the maternal endometrium. The resulting endometrial cups secrete the unusual gonadotrophin, eCG, needed to induce accessory luteal development to tide over the waning of ovarian progesterone production until such time as the placenta can assume this vital role. However, the immunological risks of this endometrial cup manoeuvre are considerable and include both high titres of antipaternal lymphocytoxic antibody in maternal serum and intense anti-fetal cell-mediated reactions in the maternal endometrium.

After taking a long time to differentiate itself and become stably attached to the endometrium, the epitheliochorial placenta must continue to grow vigorously throughout gestation to meet the increasing nutritional demands of the rapidly growing fetal foal. Microcotyledonary structures develop over the entire surface of the allantochorion to provide both haemotrophic and histotrophic forms of nutrition and yield the necessarily altricious offspring at the time of birth. Steroid hormones, and especially oestrogens, play important facilitating roles in bringing about the major 
architectural modifications to the uterus necessary to achieve such an intimate, yet extensive, system of placental exchange and, in this respect, equids show a curious parallelism to humans. The placentae of both women and mares utilize large quantities of precursors by means of the temporary enlargement and remarkable synthetic capacity of a fetal organ, the adrenal glands in women and the gonads in mares, to synthesize the very large quantities of oestrogens that, in both cases, include pregnancy-specific oestrogenic molecules.

Equids represent a fascinating contrast to the norm in terms of the fundamental physiology and essential mechanisms of pregnancy and are worthy of much closer research scrutiny in the future.

\section{References}

Key references are identified by asterisks.

Allen WR (1969) The immunological measurement of pregnant mare serum gonadotrophin Journal of Endocrinology 32 593-598

Allen WR (1975) The influence of fetal genotype upon endometrial cup development and PMSG and progestagen production in equids Journal of Reproduction and Fertility Supplement 23 405-413

Allen WR (1982) Immunological aspects of the equine endometrial cup reaction and the effect of xenogeneic pregnancy in horses and donkeys Journal of Reproduction and Fertility Supplement 31 57-94

Allen WR and Moor RM (1972) The origin of the equine endometrial cups I. Production of PMSG by fetal trophoblast cells Journal of Reproduction and Fertility 29 313-316

Allen WR and Stewart F (1993) Equine chorionic gonadotropin. In Equine Reproduction pp 81-96 Eds AO McKinnon and JL Voss. Lea and Febiger, Philadelphia

*Allen WR, Hamilton DW and Moor RM (1973) The origin of equine endometrial cups II. Invasion of the endometrium by trophoblast Anatomical Record 117 475-501

Allen WR, Kydd JH, Miller J and Antczak DF (1983) Immunological studies on feto-maternal relationships in equine pregnancy. In Immunological Aspects of Reproduction in Mammals pp 183-194 Ed. DB Crighton. Butterworth, London

Allen WR, Kydd JH, Boyle MS and Antczak DF (1987) Extra-specific donkey-in-horse pregnancy as a model of early fetal death Journal of Reproduction and Fertility Supplement 35 197-209

Allen WR, Skidmore JA, Stewart F and Antczak DF (1993) Effects of fetal genotype and uterine environment on placental development in equids Journal of Reproduction and Fertility 97 55-60

Amoroso EC (1952) Placentation. In Marshall's Physiology of Reproduction pp 127-311 Ed. AS Parkes. Longmans, Green, London

Amoroso EC, Hancock JL and Rowlands IW (1948) Ovarian activity in the pregnant mare Nature (London) 161 355-356

Antczak DF and Allen WR (1984) Invasive trophoblast in the genus Equus. In The Riddle of the Foetal Allograft Ed. G Chaouat, Annals of Immunology 135D 301-351

Antczak DF, Bright SM, Remick LH and Bauman B (1982) Lymphocyte alloantigens of the horse I. Serologic and genetic studies Tissue Antigens $20172-187$

Antczak DF, Miller JM and Remick LH (1984) Lymphocyte alloantigens of the horse II. Antibodies to ELA antigens produced during equine pregnancy Journal of Reproductive Immunology 6 283-297

Baker CB, Adams MH and McDowell KJ (1991) Lack of expression of alpha or omega interferons by the horse conceptus Journal of Reproduction and Fertility Supplement $\mathbf{4 4}$ 439-443

Battut I, Colchen S, Fieni F, Tainturier D and Bruyas JF (1998) Success rates when attempting to nonsurgically collect equine embryos at 144,156 or 168 hours after ovulation Equine Veterinary Journal Supplement 25 $60-62$
Bazer FW and Thatcher WW (1977) Theory of maternal recognition of pregnancy in swine based on oestrogen controlled endocrine versus exocrine secretion of prostaglandin $F_{2 \alpha}$ by the uterine endometrium Prostaglandins 14 397-401

Berg SL and Ginther OJ (1978) Effect of oestrogens on uterine tone and lifespan of the corpus luteum in mares Journal of Animal Science $\mathbf{4 7}$ 203-208

Betteridge KJ (1989) The structure and function of the equine capsule in relation to embryo manipulation and transfer Equine Veterinary Journal Supplement 8 92-100

Betteridge KJ and Mitchell D (1974) Direct evidence of retention of unfertilised ova in the oviduct of the mare Journal of Reproduction and Fertility 39 145-148

Bhavnani BR and Short RV (1973a) Formation of steroids by the pregnant mare III. Metabolism of ${ }^{14} \mathrm{C}$-squalene and ${ }^{3} \mathrm{H}$-dehydroisoandrosterone injected into the fetal circulation Endocrinology 92 657-666

Bhavnani BR and Short RV (1973b) Formation of steroids by the pregnant mare IV. Metabolism of ${ }^{14} \mathrm{C}$-mevalonic acid and ${ }^{3} \mathrm{H}$-dehydroisoandrosterone injected into the fetal circulation Endocrinology 92 1397-1404

Bhavnani BR, Short RV and Solomon S (1969) Formation of oestrogens by the pregnant mare I. Metabolism of $7-{ }^{3} \mathrm{H}$-dehydroisoandrosterone and ${ }^{4-14} \mathrm{C}$-androstenedione injected into the umbilical vein Endocrinology $851172-1179$

Bhavnani BR, Short RV and Solomon S (1971) Formation of estrogens by the pregnant mare II. Metabolism of ${ }^{14} \mathrm{C}$-acetate and ${ }^{3} \mathrm{H}$-cholesterol injected into the fetal circulation Endocrinology 89 1152-1157

Boulton MI, McGrath TJ, Goode JA, Broad KD and Gilbert CL (1996) Changes in content of mRNA encoding oxytocin in the pig uterus during the oestrous cycle, pregnancy, at parturition and in lactational anoestrus Journal of Reproduction and Fertility 108 219-227

*Bracher V, Mathias S and Allen WR (1996) Influence of chronic degenerative endometritis (endometrosis) on placental development in the mare Equine Veterinary Journal 28 180-188

Clegg MT, Boda JM and Cole HH (1954) The endometrial cups and allantochorionic pouches in the mare with emphasis on the source of equine gonadotrophin Endocrinology 54 448-463

Cole HH and Goss H (1943) The source of equine gonadotropin. In Essays in Honor of Herbert M Evans pp 107-119. University of California Press, Berkeley

Cole HH and Hart GH (1930) The potency of blood serum of mares in progressive stages of pregnancy in effecting the sexual maturity of the immature rat American Journal of Physiology 93 57-68

Cole HH, Howell CE and Hart GH (1931) The changes occurring in the ovary of the mare during pregnancy Anatomical Record 49 199-209

Cole HH, Hart GH, Lyons WR and Catchpole HR (1933) The development and hormonal content of fetal horse gonads Anatomical Record $\mathbf{5 6}$ 275-293

Cox JE (1975) Oestrone and equilin in the plasma of the pregnant mare Journal of Reproduction and Fertility Supplement 23 463-468

Crump A, Donaldson WL, Miller JM, Kydd JH, Allen WR and Antczak DF (1987) Expression of major histocompatibility complex (MHC) antigens on horse trophoblast Journal of Reproduction and Fertility Supplement 35 379-388

Daels PF, DeMoraes JJ, Stabenfeldt GH, Hughes JP and Lasley BL (1991) The corpus luteum: source of oestrogen during early pregnancy in the mare Journal of Reproduction and Fertility Supplement 35 501-508

David JSE (1975) A survey of eggs in the oviducts of mares Journal of Reproduction and Fertility Supplement 23 513-517

Denker HW, Betteridge KJ and Sirois J (1987) Shedding of the capsule and proteinase activity in the horse embryo Journal of Reproduction and Fertility Supplement 35703 (Abstract)

Diczfalusy E (1969) Steroid metabolism in the feto-placental unit. In The Foeto-placental Unit pp 65-109 Eds A Peciles and C Finzi. Excerpta Medica Foundation, Amsterdam

Donaldson WL, Zhang CH, Oriol JG and Antczak DF (1990) Invasive equine trophoblast expresses conventional class I major histocompatibility complex antigens Development 110 63-71

Evans MJ and Irvine CHG (1975) Serum concentrations of FSH, LH and 
progesterone during the oestrous cycle and early pregnancy in the mare Journal of Reproduction and Fertility Supplement 23 193-200

Ewart JC (1897) A Critical Period in the Development of the Horse Adam and Charles Black, London

Ewart JC (1915) Studies on the development of the horse I. The development during the third week Transcripts of the Royal Society of Edinburgh 51 287-329

Flint APF and Sheldrick EL (1982) Ovarian secretion of oxytocin is stimulated by prostaglandins Nature 297 587-588

Flood PF, Jong A and Betteridge KJ (1979a) The location of eggs retained in the oviducts of mares Journal of Reproduction and Fertility 57 291-294

Freeman DA, Woods GL, Vanderwall DK and Weber JA (1992) Embryoinitiated oviductal transport in the mare Journal of Reproduction and Fertility 95 535-538

Gaudry R and Glen WL (1959) Sur la fraction steroide de I'urine de la jument gravide Étude Belge Supplement 2 435-440

*Gerstenberg C, Allen WR and Stewart F (1999) Factors controlling epidermal growth factor (EFG) gene expression in the endometrium of the mare Molecular Reproduction and Development 53 255-265

Ginther OJ (1983a) Mobility of the early equine conceptus Theriogenology 19 603-611

Ginther OJ (1983b) Fixation and orientation of the early equine conceptus Theriogenology 19 613-623

Ginther OJ (1985) Dynamic physical interactions between the equine embryo and uterus Equine Veterinary Journal Supplement 3 41-47

Ginther OJ, Garcia MC, Squires EL and Steffenhagen WP (1972) Anatomy of vasculature of uterus and ovaries in the mare American Journal of Veterinary Research 33 1561-1568

Goff AK, Pontbriand D and Sirois J (1987) Oxytocin stimulation of plasma 15-keto-13,14-dihydro prostaglandin $F_{2 \alpha}$ during the oestrous cycle and early pregnancy in the mare Journal of Reproduction and Fertility Supplement 35 253-260

Gospodorowicz D (1972) Purification and physiochemical properties of the pregnant mare serum gonadotrophin (PMSG) Endocrinology 91 101-106

Grünig GG, Triplett L, Canady LK, Allen WR and Antczak DF (1995) The maternal leucocyte response to the endometrial cups in horses is correlated with the developmental stages of the invasive trophoblast cells Placenta 16 539-559

Hamilton DW, Allen WR and Moor RM (1973) The origin of the equine endometrial cups III. Light and electron microscopic study of fully developed equine endometrial cups Anatomical Record 117 503-518

Hansen TR, Austin KJ, Perry DJ, Pru JK, Teixeira MG and Johnson GA (1999) Mechanism of action of interferon-tau in the uterus during early pregnancy Journal of Reproduction and Fertility Supplement $\mathbf{5 4}$ 329-339

Hay MF and Allen WR (1975) An ultrastructural and histochemical study of the interstitial cells in the gonads of the fetal horse Journal of Reproduction and Fertility Supplement 23 557-561

Heap RB, Hamon M and Allen WR (1982) Studies on oestrogen synthesis by the preimplantation equine conceptus Journal of Reproduction and Fertility Supplement 32 343-352

Holtan DW, Squires EL, Lapin DR and Ginther OJ (1979) Effect of ovariectomy on pregnancy in mares Journal of Reproduction and Fertility Supplement 27 457-463

Kydd J, Miller J, Antczak DF and Allen WR (1982) Maternal anti-fetal cytotoxic antibody responses of equids during pregnancy Journal of Reproduction and Fertility Supplement 32 361-369

Kydd J, Butcher GW, Antczak DF and Allen WR (1991) Expression of major histocompatibility complex (MHC) class I molecules on early equine trophoblast Journal of Reproduction and Fertility Supplement 44 463-477

Lamming GE and Mann GE (1995) Control of endometrial oxytocin receptors and prostaglandin $\mathrm{F}_{2 \alpha}$ production in cows by progesterone and oestradiol Journal of Reproduction and Fertility 103 69-73

Lamming GE, Wathes DC, Flint APF, Payne JH, Stevenson KR and Vallet JL (1995) Local action of trophoblast interferons in suppression of the development of oxytocin and oestradiol receptors in ovine endometrium Journal of Reproduction and Fertility 105 165-175

Lennard SN, Stewart F and Allen WR (1995) Insulin-like growth factor II gene expression in the fetus and placenta of the horse during the first half of gestation Journal of Reproduction and Fertility 103 169-179

Lennard SN, Gerstenberg C, Allen WR and Stewart F (1998) Expression of epidermal growth factor and its receptor in equine placental tissues Journal of Reproduction and Fertility 112 49-57

McCracken JA, Schramm W and Okulicz WC (1984) Hormone receptor control of pulsatile secretion of $\mathrm{PGF}_{2 \alpha}$ from the ovine uterus during luteolysis and its abrogation in early pregnancy Animal Reproduction Science 7 31-55

Macdonald AA, Chavatte $\mathbf{P}$ and Fowden AL (2000) Scanning electron microscopy of the microcotyledonary placenta of the horse (Equus caballus) in the latter half of gestation Placenta 21 565-574

McDowell KJ, Sharp DC, Peck LJ and Cheves LL (1985) Effect of restricted conceptus mobility on maternal recognition of pregnancy in mares Equine Veterinary Journal Supplement 3 23-24

McKinnon AO, Carnevale EM, Squires EL, Carney NJ and Seidel GE (1989) Bisection of equine embryos Equine Veterinary Journal Supplement 8 129-133

Merchant-Larios H (1979) Ultrastructural events in horse gonadal morphogenesis Journal of Reproduction and Fertility Supplement $\mathbf{2 7}$ 479-485

Moor RM (1968) Effect of embryos on corpus luteum function Journal of Animal Science Supplement 1 97-118

Morris LH-A and Allen WR Reproductive efficiency in the Thoroughbred Equine Veterinary Journal (in press)

Onuma H and Ohnami Y (1975) Retention of tubal eggs in mares Journal of Reproduction and Fertility Supplement 23 507-511

Oriol JG, Sharom FJ and Betteridge KJ (1993a) Developmentally regulated changes in the glycoproteins of the equine embryonic capsule Journal of Reproduction and Fertility $99653-664$

Oriol JG, Betteridge KJ, Clarke AJ and Sharom FJ (1993b) Mucin-like glycoproteins in the equine embryonic capsule Molecular Reproduction and Development 34 255-265

Pashen RL and Allen WR (1979) The role of the fetal gonads and placenta in steroid production, maintenance of pregnancy and parturition in the mare Journal of Reproduction and Fertility Supplement 27 499-509

Perry JS, Heap RB and Amoroso EC (1973) Steroid hormone production by pig blastocysts Nature 245 45-47

Pupkin MJ, Schomberg DW, Nagey DA and Crenshaw C (1975) Effects of exogenous dehydroepiandrosterone upon feto-placental biosynthesis of estrogens and its effect upon uterine blood flow in the term pregnant ewe American Journal of Obstetrics and Gynecology 121 227-232

Raeside JI and Liptrap RM (1975) Patterns of urinary oestrogen excretion in individual pregnant mares Journal of Reproduction and Fertility Supplement 23 469-475

Resnik R, Killam AP, Battaglia FC, Makowski EL and Meschia G (1974) The stimulation of uterine blood flow by various oestrogens Endocrinology 94 1192-1196

Robinson SJ, Neal H and Allen WR (2000) Modulation of oviductal transport in the mare by local application of prostaglandin $\mathrm{E}_{2}$ Journal of Reproduction and Fertility Supplement 56 587-592

Rowlands IW (1963) Levels of gonadotrophin in tissues and fluids with emphasis on domestic animals. In Gonadotrophins: Their Chemical and Biological Properties and Secretory Control pp 74-112 Ed. HH Cole. WH Freeman and Co., San Francisco

Samuel CA, Allen WR and Steven DH (1974) Studies on the equine placenta I. Development of the micro-cotyledons Journal of Reproduction and Fertility 41 441-445

Samuel CA, Allen WR and Steven DH (1975) Ultra-structural development of the equine placenta Journal of Reproduction and Fertility Supplement 23 575-578

Samuel CA, Allen WR and Steven DH (1976) Studies on the equine placenta II. Ultrastructure of the placental barrier Journal of Reproduction and Fertility 48 257-264

Samuel CA, Allen WR and Steven DH (1977) Studies on the equine placenta III. Ultrastructure of the uterine glands and the overlying trophoblast Journal of Reproduction and Fertility 51 433-437

Schauder W (1912) Untersuchungen über die eithäute und embryotrophe des pferdes Archives of Anatomy and Physiology (1912) 259-302 
Seidel GE (1997) Cryopreservation of equine embryos Veterinary Clinics of North America: Equine Practice 12 85-99

Short RV (1969) Implantation and the maternal recognition of pregnancy. In Ciba Foundation Symposium on Foetal Autonomy pp 2-26 Eds GEW Wolstenholme and $\mathrm{M} \mathrm{O}^{\prime}$ Connor. J and A Churchill, London

Skidmore JA, Boyle MS, Cran D and Allen WR (1989) Micromanipulation of equine embryos to produce monozygotic twins Equine Veterinary Journal Supplement 8 126-128

Skidmore JA, Boyle MS and Allen WR (1991) A comparison of two different methods of freezing horse embryos Journal of Reproduction and Fertility Supplement $\mathbf{4 4}$ 714-716

Starbuck GR, Stout TAE, Lamming GE, Allen WR and Flint APF (1998) Endometrial oxytocin receptor and uterine prostaglandin secretion in mares during the oestrous cycle and early pregnancy Journal of Reproduction and Fertility 113 173-179

Steven DH and Samuel CA (1975) Anatomy of the placental barrier in the mare Journal of Reproduction and Fertility Supplement 23 579-582

Stewart F, Allen WR and Moor RM (1976) Pregnant mare serum gonadotrophin: ratio of follicle-stimulating hormone and luteinizing hormone activities measured by radioreceptor assay Journal of Endocrinology 71 371-382

Stewart F, Charleston B, Crossett B, Barker PJ and Allen WR (1995a) A novel uterine protein that associates with the blastocyst capsule in equids Journal of Reproduction and Fertility 105 65-70

Stewart F, Lennard SN and Allen WR (1995b) Mechanisms controlling formation of the equine chorionic girdle Biology of Reproduction Monograph Series 1 151-159

Stout TAE (1997) Maternal Recognition of Pregnancy in the Mare PhD Thesis, University of Cambridge

Stout TAE and Allen WR (1996) Conceptus factors involved in the maternal recognition of pregnancy in the mare Journal of Reproduction and Fertility Abstract Series 1753

Stout TAE, Lamming GE and Allen WR (2000) Oxytocin and its endometrial receptor are integral to luteolysis in the cycling mare Journal of Reproduction and Fertility Supplement 56 281-287

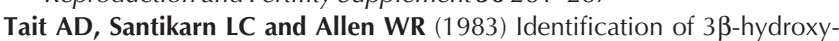
5,7pregnandien-20-one and 3 $\beta$-hydroxy-5,7androstadien-17-one as endogenous steroids in the foetal horse gonad Journal of Endocrinology 99 87-92
Terqui M and Palmer E (1979) Oestrogen pattern during early pregnancy in the mare Journal of Reproduction and Fertility Supplement $\mathbf{2 7}$ $441-446$

Urwin VE and Allen WR (1982) Pituitary and chorionic gonadotrophin control of ovarian function during early pregnancy in equids Journal of Reproduction and Fertility Supplement 32 371-382

van Niekerk CH (1965) The early diagnosis of pregnancy, the development of foetal membranes and nidation in the mare Journal of the South African Veterinary Medicine Association 36 483-488

van Niekerk CH and Allen WR (1975) Early embryonic development in the horse Journal of Reproduction and Fertility Supplement 23 495-498

van Niekerk CH and Gerneke WH (1966) Persistence and parthenogenetic cleavage of tubal ova in the mare Onderstepoort Journal of Veterinary Research 33 195-231

Wathes DC and Swann RW (1982) Is oxytocin an ovarian hormone? Nature (London) 297 225-227

Watson ED, Bjorkstein TS, Buckingham J and Nikolakopoulos E (1997) Immunolocalisation of oxytocin in the uterus of the mare Journal of Reproduction and Fertility Abstract Series 2031

Webel SK, Hamblin V, Harland B and Dzuik PJ (1977) Fertility, ovulation and maturation of eggs in mares injected with hCG Journal of Reproduction and Fertility 51 337-341

Weber JA, Freeman DA, Vanderwall DK and Wood GL (1991a) Prostaglandin $\mathrm{E}_{2}$ secretion by oviductal transport-stage equine embryos Biology of Reproduction 45 540-543

Weber JA, Freeman DA, Vanderwall DK and Wood GL (1991b) Prostaglandin $\mathrm{E}_{2}$ hastens oviductal transport of equine embryos Biology of Reproduction 45 544-546

Weber JA, Woods GL, Freeman DA and Vanderwall DK (1992) Prostaglandin $\mathrm{E}_{2}$-specific binding to the equine oviduct Prostaglandins 43 61-65

Weber JA, Woods GL and Lichtenwalner AB (1995) Relaxatory effect of prostaglandin $E_{2}$ on circular smooth muscle isolated from the equine oviductal isthmus Biology of Reproduction Monograph 1 125-130

Wooding FBP (1982) The role of the binucleate cell in ruminant placental structure Journal of Reproduction and Fertility Supplement 31 31-39

Woodley SL, Burns PJ, Douglas RH and Oxender WD (1979) Prolonged interovulatory interval after oestradiol treatment in mares Journal of Reproduction and Fertility Supplement 27 205-209 